\title{
Meditation, Breath Work, And Focus Training For Teachers And Students - The Five Minutes A Day That Can Really Make A Difference
}

Sandra A. Sessa, (E-mail: sessas@georgian.edu), Georgian Court University

\begin{abstract}
This paper is based on information researched and presented in a faculty development seminar for elementary teachers for use with students preparing for national testing to manage stress and increase attention focus. It reviews effects of stress on behavior, mood, and concentration; explains basics of breath work and meditation; provides meditation instructions in a simple and direct way; and describes how to use the techniques in the classroom. Statements from the principal, as well as workshop evaluations and follow up communications regarding the training, were very positive. It appears both teachers and students are receptive to the use of meditation, breath work, and focus training - the five minutes a day that can really make a difference for teachers and students.
\end{abstract}

\section{INTRODUCTION}

\&

n today's fast paced, stress filled world, with its continuously increasing performance demands, time constraints, and limited resources, there is evidence of widespread effects of these stresses on our everyday functioning and health, leading to a need for an effective antidote. The present paper is aimed at describing some of these effects of stress on behavior, mood, and concentration in adults, and illustrating similar negative effects in children. It then offers a rationale for the use of meditation, breath work, and focus training as effective tools for reducing these effects of stress. Lastly, it describes a teacher in-service training workshop for elementary school faculty who were preparing their students for statewide mandatory testing, where meditation instruction was provided for the teachers for their own use as well as strategies for using meditation and breath work with their students.

Stress is a part of life - and it is not all bad. In fact, a bit of stress can tweak our performance. It can give us the "edge" when we take off at the start of a race or run to catch a train. It sets the "fight or flight" mechanism into play, pushes the stress hormone cortisol into our system, and on a short term basis, that is just fine. As soon as we run the race or catch the train our system calms down and life goes back to normal and so does our body's functioning. But, life is not like that for most of us. All too often we are in states of constant arousal; states of stress. Multitasking seems to have become a new religion. During a visit to a young family's home during football season the dad was excited to be watching "the games" - eight at one time! On a split screen TV. That calls for attention constantly shifting among eight mini screens - for the purpose of "seeing it all". This Sunday afternoon family activity seemed more like the daily work experience of an air traffic controller watching multiple aircrafts, a job known to be highly stress laden. Our bodies are not made for that kind of wear and tear. Add to that other "real world reasons" for stress - the divorce rate - about every other marriage in the United States ends in divorce today; the stress of unemployment, infertility - some say that one in every four couples who wants to have a baby today is having difficulty; terrorism, natural disasters, housing prices, and on top of that, if you are an educator, you need to be concerned with your students' learning and performance. In education too there are higher expectations from administrators, and from parents - to do it well, do it faster, get better results, and leave no child behind. 
So what happens? Our bodies and minds react with symptoms. Our spirits respond as well, but it is beyond the scope of this paper to address the spiritual element. Johnson (1997) delineates twenty-six psychological symptoms including difficulty concentrating, agitation, feeling overwhelmed, and sexual dysfunction, as well as twenty-five physical symptoms such as headaches, muscles tension, sleep disturbance, and fatigue, as symptoms people may experience in her Survey of Stress Symptoms (P. 245). We find that we become just a bit more irritable, out of sorts, more easily frustrated, cranky, and impatient. We get migraines, upset stomachs, back aches, have difficulty sleeping or get just plain moody. The lack of sleep alone can impact our concentration and work performance. And under stress our appetite is impacted. Some people experience a diminished appetite and others grab for comfort foods. The impact on our blood sugar can effect our concentration as well as our memory. Roizen and $\mathrm{Oz}$ (2005) tell us that illness comes from these constant stresses. Over the long term we can see hypertension, raised cholesterol levels, anxiety disorders, and depression. They assert, "Nagging stress wears you out, while persistent stressors are true killers" (p. 93).

As you can imagine, all of these conditions can lead to difficulty with coworkers or students, and can also cause higher rates of absenteeism. Relationships suffer under the distress of prolonged stress promoted illness. There is another piece to this scenario. We used to think that stress only affected adults. We would like to think that childhood is a time to be carefree and happy - a time without the stress demands that we all face as adults - but really, we now know that our children are under as much pressure as the rest of us. Children experience pressure from parents and teachers to do well, achieve academically, get the homework done, hand in the projects on time, get good grades, stay out of trouble, etc. And there is more to our children's stress - from teasing, bullying, constant bombardment with noise from TV and video games, and for some, rushing from one after school activity to another. For many of our children, the only quiet time they get is when they are asleep - if they can fall of to sleep and sleep soundly with all the tension they experience. And the effects of a lack of sleep are as serious, if not more so for children than they are for adults. For example, human growth hormone, important to growth and development in children, is released during sleep. A lack of sleep can be problematic.

We also now have evidence that the affects of long term stress in adults often have their beginnings in childhood. As Tolan and Dodge indicated I their 2005 work, "Child mental health problems often persist into adulthood, and most adult disorders are preceded by child mental health problems" (Tolan \& Dodge, 2005, p.605). Children's mental health is of great importance, yet exposure to ongoing life stress appears to be taxing our children, often to a point of dysfunction. Parents seek medical and psychological treatment for their children for many stress related difficulties. While a disproportionate amount of the $\$ 85.4$ billion per year of our national health care dollars are spent on adults (as opposed to being equally spread among children, adolescents and adults) for mental health care, $\$ 11.7$ billion is spent on people under 21(Tolan \& Dodge, 2005).

So, what are we to do? It appears that there is no escape from stress and its effects. The situation seems to go like this - If you are human, you have stress! We, and our children, are just destined to fall apart, suffer awful symptoms, not be able to concentrate or remember anything and generally be miserable due to the pace and stress of every day living...end of story, right? Not exactly. We need to relax de-stress, become more focused, and improve our general lifestyle and health in order to reduce the likelihood of these symptoms and disorders occurring. But how do we do that? Many researchers, medical and psychological clinical practitioners, spiritual guides and leaders, as well as educators, believe that breath work and meditation can fit the bill. Breath work and meditation may provide the cost effective, drug free, antidote we need. Let's take a look at these possibilities.

\section{WHAT THE LITERATURE SAYS ABOUT BREATH WORK AND MEDITATION}

Breathing happens automatically with no special assistance, or it can occur with our purposeful control. It is both conscious and unconscious. When anxious, tense, or distressed, the breath becomes rapid and shallow. Watch a person who is angry or frightened; notice the quick rise and fall of the breath high up in the chest. Then observe a person in a deeply relaxed state or someone who is sleeping comfortably. The breath is much deeper, slower, and even, expanding the abdomen. Breath work, the conscious regulation of our breath, is a very effective way to begin to promote relaxation and achieve a clear state of mind. Simply slowing our breath can have many 
benefits. In fact, breath training is one of the alternative treatments recommended for relief of both insomnia and anxiety according to Miller, Editor in Chief of the Harvard Mental Health Letter (2005).

Weil (2006) suggests "Practicing regular, mindful breathing can be calming and energizing and can even help with stress related health problems ranging from panic attacks to digestive disorders" (p.1). He recommends a simple and teachable 4-7-8 breathing pattern; inhaling through the nose for a count of 4 , holding the breath for a count of 7 , and exhaling through the mouth to a count of 8 . This pattern tends to slow the breath. Weil says that this exercise is a "natural tranquilizer for the nervous system" (p.1) done easily and without the use of medication. He recommends doing the exercise for four rounds at a time increasing to eight rounds over time, and at least twice a day. Unlike tranquilizers that tend to lose their effect with prolonged use, the opposite seems to happen with this breath work. The calming effect gains strength. Breath Counting is another type of breath work that has beneficial relaxing effects. Simply inhale through the nose and exhale through the mouth and as you exhale, mentally count the breaths 1 through 5. After the fifth breath go back to counting from 1 to 5 as you exhale each breath again. The mental discipline is to keep your attention focused on the out breath and only count up to 5 breaths. If you find yourself counting $9,10,11$, breaths, you know you have lost your focus. Simply and gently guide your focus back to counting the breaths with 1.This can be done for several rounds and can be very useful just prior to going to sleep or any time we need to calm the mind (Weil, 2006).

Now, what about meditation? How might that be useful? First, we need to clarify that there are many types of meditation. One that has been researched widely is called Transcendental Meditation (TM), which has its roots in Hinduism, but demands no religious affiliation for its practice and benefits. For adults, TM involves sitting quietly with your eye closed and mentally repeating a word or phrase, termed a "mantra", twice a day for twenty minutes. If thoughts intrude, or even if you fall asleep, you simply go back to the mantra once you realize that you have not been saying it. For children, it is advised that they do it while walking or playing quietly for only a few minutes at a time. Five minutes at age five is recommended, while adding one minute per year of their age (Selby, 2006).

A second type of meditation that is fairly widely used today is Mindfulness Awareness Meditation. It has been shown to be related to very positive psychological and physical outcomes (Brown \& Ryan (2003). Mindfulness has its roots in Buddhism and other contemplative traditions and is most commonly defined as "...the state of being attentive to and aware of what is taking place in the present" (p. 822). It is a mental focusing discipline where the attention is brought back to one focus over and over; often the breath is the focus. Again, it is not essential to have a religious basis to use this form of meditation. Research studies supporting positive effects of meditation have burgeoned over the past decade. A small sampling of examples follows.

In an article by Davis (2005) she refers to a quote by the well known cardiologist and founder of Harvard's Mind/Body Institute Herbert Benson, who strongly asserts "Any condition that's caused or worsened by stress can be alleviated through meditation" (p. 1). Benson is credited with over three decades of research regarding the body's relaxation response and tells us that it lowers blood pressure, improves heart rate, breathing, and brain waves. Meditation is also credited with reducing the effects of premenstrual syndrome (PMS) and improving milk flow in lactating mothers. There are many other studies that add support to Benson's position. Some have raised caveats.

Meditation can improve immune system functioning according to Davidson et al. (2003) who conducted a study where a group of participants who were trained in meditation for eight weeks and were encouraged to practice for an hour each day six days per week at home, produced more antibodies to a flu vaccine than their counterparts who received the vaccine but did not practice meditation. The meditation group also showed more of the type of brain activity that is associated with positive feelings and reduction in anxiety. Smith (2004) reacted to this study with concerns that meditation methods are not being clearly differentiated one from another, so there is confusion as to what is being effective, as well as the lack in the study of a comparison group who enjoyed other pleasurable activities rather than meditation. Again, this creates confusion as to what was really responsible for the boost in the immune system response and positive brain function. Could other pleasurable activities create the same response as the meditation did? Other researchers continue to investigate these issues. Smith also added that his research has found at least fifteen positive states associated with mediation and mindfulness such as peace, mental quiet, love, being energized, and refreshed, in addition to happiness. These studies and a whole host of others yield many 
positive benefits of meditation with adults. There is also research showing positive effects with adolescents and younger children.

Barnes (2004) with a group of researchers investigated the impact of meditation on blood pressure and heart rate in adolescents. One group of participants was assigned to the meditation group where they meditated 10 minutes a day at school and at home after school for three months, and the other was assigned to a health education control group for 20 minutes per day to learn about prevention of hypertension. The results showed significant ( $<$ < .05) differences in average change from pretest to posttest between the mediation and health education control groups for resting systolic blood pressure, daytime ambulatory systolic blood pressure after school, daytime ambulatory diastolic blood pressure after school and daytime ambulatory heart rate after school. The study came to the conclusion that, "These findings demonstrate the potential beneficial impact of meditation on blood pressure and heart rate in the natural environment in healthy normotensive youth" (p. 2). The researchers state that the meditation technique can be easily learned, implemented in the classroom by a teacher, and practiced at no cost. In addition, there are reports of reduction in school absences as well as fewer conduct problems in addition to the lowering of blood pressure and heart rate. These are very beneficial results.

Lisa Desmond (2004), teacher of preschool children, author, and meditation practitioner, states, "I have observed children who are in pain from the loss of a loved one, children who are sad, fearful, hyperactive, or angry, become calm, relaxed, and at peace with themselves and the world around them through meditation" (p.xvii). She further credits meditation with helping children fall asleep and calming them when they are afraid or worried as well as assisting them with learning difficulties and attention deficits. This is high praise for a technique that once learned, can be practiced free of charge, with many positive benefits and no ill side effects.

Maureen Garth (1991), reflecting on teaching meditation to eight year old children states her belief that "meditation could be very constructive in harnessing the thoughts of children who tend to scatter their energies in directions that are not productive" ( $\mathrm{p} \mathrm{.9).} \mathrm{Twenty} \mathrm{minutes} \mathrm{is} \mathrm{recommended} \mathrm{for} \mathrm{full} \mathrm{benefit,} \mathrm{of} \mathrm{calmness,} \mathrm{tension}$ relaxing, and the relief from anxiety that comes with detaching from our problems, but five to ten minutes can be ample if that is what you have available. She praises meditation for providing a "... relaxing way of coping with the stress and anxiety" of our day to day lives (p. 16).

\section{THE BASICS OF MEDITATION - WHAT IT IS AND HOW TO DO IT}

First, let's discuss the term "meditation". Walsh and Shapiro (2006) state that there are numerous ways of defining the process. Common themes emerge when attempting to formulate a comprehensive definition, such as "self-regulation strategy with a focus on training attention" (p. 228) or cultivating beneficial mental capacities such as calm and concentration, and "positive emotions such as love and joy" (p. 228). They found that by integrating these themes they could create a meaningful definition. They state that the term (meditation) refers to ".... family of self-regulating practices that focus on training attention and awareness in order to bring mental processes under greater voluntary control and thereby foster general mental well-being and development and/or specific capacities such as calm, clarity, and concentration" (p. 229). Their comprehensive article states that over the past forty years, literally hundreds of studies have investigated meditation and its beneficial effects. While there are many forms of meditation, this paper will focus on a very simple mindfulness awareness meditation that can be easily learned and practiced. The directives are this. Generally sit either crossed legged on a pillow or the floor or in a comfortable chair. Keep the back and head straight. The eyes can be closed or open with a slightly downward gaze about four to six feet ahead of you. The mouth is opened just slightly allowing the breath to flow out easily. The hands are resting on the thighs or are in an open hand in palm fashion in the lap. All breaths are in through the nose and out through the mouth. The mental focus is on the out breath. As thoughts arise, as they will, because the nature of mind is to think, simply notice that you are thinking and say to yourself "thinking" and return your focus to your out breath. Continue this pattern for several minutes twice a day at the beginning. Overtime, increase the amount of "sitting time" to 20 to 30 or 45 minutes. For an excellent detailed audio tape of instructions for meditation refer to Pema Chodron's Pure Meditation by Sounds True. 


\section{MEDITATION FOR TEACHERS AND THEIR STUDENTS}

A one-hour teacher in-service workshop on meditation, breath work and focus training was presented to teachers of elementary grades three, four and five as a stress management strategy for personal use and for use with their students who were preparing for mandatory statewide testing. The school principal also attended the workshop. Generally, the information presented in this paper was presented to the teachers and basic breath work was demonstrated and practiced. Using an active learning strategy that Sessa (2005) reported as effective and enhancing of learning, an interactive period followed where the teachers shared their experiences with the breath work and questions were addressed. Then, the mindfulness awareness meditation directives were given and soft music was played on a portable CD player. The participants continued the meditation period for several minutes. A discussion was held after the mini session and the responses were very positive including statements like "It was so relaxing", "That was really good", and "I can't wait to try this with my class". Some teachers were already using meditative time or breath work with their students and commented positively on their experiences. Evaluations were completed with $100 \%$ of the participants reporting that they agreed or totally agreed with the statement "I now have a better understanding about how breath work can reduce stress" and the vast majority (92\%) of the participants agreeing with or totally agreeing with the statement "I believe that teaching breathing exercises or meditation to my students could be useful to them. Finally, $85 \%$ of the participants either agreed or totally agreed with the statement "I now have some understanding of how I can practice meditation". A sampling of the comments or suggestion for the presenter on the evaluation sheets included "Can't wait to teach the breathing to my class! Thank you for a stress free morning"; "Very interesting and informative. I will try this with myself, my students and my family"; and "It works!" Lastly, a letter from the principal was received by the presenter where he stated, "Our school has just completed the State required testing for grades $3 \& 4$ and the environment in the school was calm and relaxed. I feel your information had a tremendous impact on that occurring...Y Your efforts have already proved to make an impact on the staff and in turn, a positive impact on the students" (personal communication, 2006).

The paper presented here has described the effects of stress on behavior, mood, and concentration and given a rationale for the use of meditation, breath work and focus training as effective tools for reducing the effects of stress and has described a teacher in-service workshop centered around breath work and meditation. Responses to the workshop from the participants, as well as the principal, were very positive. While the workshop was well received and adds to our body of knowledge about the positive effects of breath work and meditation, future efforts need to be made with larger groups. It would appear that entire schools could benefit from breath work and meditation - the five minutes a day that can really make a difference. It is likely that fifteen or twenty minutes would be even more beneficial, but positive results can be experienced in as little as five minutes of focused attention for breath work or meditation. And remember, it is easily learned, quite beneficial, and very cost effective!

\section{REFERENCES}

1. $\quad$ Brown, K.W. \& Ryan, R.M. (2003). The benefits of being present: Mindfulness and its role in psychological well-being. Journal of Personality and Social Psychology, 84, 822-848.

2. $\quad$ Chodron, P (1998). Pure Meditation. Sounds True.

3. Corsini, R.J. \& Wedding, D. (1995) Current Psychotherapies. $\left(5^{\text {th }}\right.$ ed.) Illinois: Peacock.

4. Davidson, R.,Kabat-Zinn, J., Schumacher, J., Rosenkranz, M., Muller, D., Santorelli, S., Urbanowski, F., Harrington, A., Bonus, K., Sheridan, J. (2003) Alterations in brain and immune function produced by mindfulness meditation. Psychosomatic Medicine, 65, 564-570.

5. Davis, J.L. (1999). Meditation balances the body's systems. WebMD. www.webmd.com/content/Article/99/105340. retrieved 3/16/2006.

6. Desmond, L. (2004). Baby Buddhas - A Guide to Teaching Meditation to Children. Kansas City: Andrews McMeel Publishing.

7. DrWeil.com - www.drweil.com/u/Article/M114Print/retrieved 1/27/2006.

8. DrWeil.com -www.drweil.com/u/Article/M115Print / retrieved 1/27/2006.

9. DrWeil.com - www.drweil.com/u/Article/M116Prinft / retrieved 1/27/2006.

10. Eastlack, J.W. (2005). Anxiety - Diagnosis, Treatment and Prevention. Tennesee: Cross Country Education, Inc. 
11. Flexner, S.B. (1983).The Random House Dictionary (concise edition). New York: Random House.

12. Fraser, L. (2006). Can a hothead breathe away her inner demons? Health, 20, 124-125.

13. Garth, M. (1991). Starbright-Meditations for Children. SanFrancisco: Harper.

14. Johnson, S. (1997). Therapist's Guide to Clinical Intervention. New York: Academic Press.

15. Miller, M.C. (2005). Benzodiazepines (and the althernatives). Harvard Mental Health Letter, 22, 4.

16. Nhat Hanh,T. (1987). The Miracle of Mindfulness. Boston: Beacon Press.

17. Roizen, M. \& Oz, M. (2005). You - The Owner's Manual. New York: Harper Collins.

18. Rozman, D. (1994). Meditating with Children- The Art of Concentration and Centering. California: Planetary Publishers.

19. Selby,A. - Meditation for children. www.ivillage.co.uk/parenting/school retrieved 1/22/06.

20. Sessa, S. (2005). Strategies designed to promote active learning and student satisfaction. Journal of College Teaching and Learning, 2, 7-11.

21. Smith, J. C. (2004). Alterations in brain and immune function produced by mindfulness meditation: Three caveats. Psychosomatic Medicine, 66, 148-149.

22. Tolan, P.H. \& Dodge, K.A. (2005). Children's mental health as a primary care and concern. American Psychologist, 60, 601-614.

23. Walsh, R. \& Shapiro, S. (2006). The meeting of meditative disciplines and western psychology. American Psychologist, 61, 227-239.

\section{NOTES}

